\title{
PENGARUH SENAM KAKI DIABETIK TERHADAP PENURUNAN RISIKO ULKUS DIABETIKUM PADA PASIEN DIABETES MELLITUS TIPE 2 DI PUSKESMAS TAUPAH BARAT KECAMATAN TAUPAH BARAT KABUPATEN SIMEULE TAHUN 2020
}

\author{
Yulis Hati $^{1}$, Dirayati Sharfina ${ }^{2}$, Zamawawi ${ }^{3}$
}

STIKes Rumah Sakit Haji Medan, Indonesia

Article Info

Keywords:

Diabetic Exercise Risk of Diabetic Ulcer

\begin{abstract}
Diabetes mellitus is a chronic disease that cannot be cured but can be controlled which can cause various complications. To reduce the risk of complications due to diabetes mellitus, diabetes exercise exercises can be done. This study aims to find out the Effect of Diabetic Foot Gymnastics on Reducing the Risk of Diabetic Ulcer in Type 2 Diabetes Mellitus Patients in West Taupah Health Center, West Taupah District, Simeule Regency 2020.This study uses a PreExperimental. The population in this study were all people with diabetes mellitus who visited the West Taupah Health Center as many as 32 people. The sampling technique used a purposive sampling technique of 20 people. The results showed that the risk of diabetic ulcers before the implementation of diabetes foot exercises at the West Taupah Health Center was mostly high risk. The risk of diabetic ulcers after the implementation of diabetes foot exercises at the West Taupah Health Center was mostly low risk. There is an Influence before and after the implementation of Diabetic Foot Gymnastics on the Reduction of the Risk of Diabetic Ulcer in Type 2 Diabetes Mellitus Patients in West Taupah Health Center, West Taupah Subdistrict, Simeule Regency in 2020 with $p=0.0001<\alpha=$ 0.05.Suggestions in this study, especially for health workers should continue to try to do diabetic foot exercises on a scheduled basis in order to minimize the risk of diabetic ulcers.
\end{abstract}

This is an open access article under the CC BY-SAlicense.

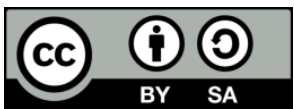

\section{Corresponding Author:}

Yulis Hati,

Program Studi D-III Kebidanan,

STIKes Rumah Sakit Haji Medan,

Jl. Rumah Sakit H., Medan Estate, Kec. Percut Sei Tuan, Kabupaten Deli Serdang, Medan-Sumatera Utara. Email: yoelisht@gmail.com

\section{INTRODUCTION}

Diabetes Mellitus (DM) merupakan penyakit gangguan metabolik terutama metabolisme karbohidrat yang disebabkan oleh berkurangnya atau ketiadaan hormon insulin dari sel beta pankreas, atau akibat gangguan fungsi insulin, atau keduanya (Sutedjo, 2010). 
Penyakit DM Tipe 2 merupakan penyakit kronis yang tidak dapat disembuhkan akan tetapi dapat dikendalikan. Pengendalian penyakit ini salah satunya adalah dengan senam kaki diabetik. Menurut Ruben, dkk (2016) menyebutkan bahwa empat pilar penatalaksanaan diabetes yaitu edukasi, terapi gizi medis, latihan jasmani, dan terapi farmakologi. Komponen latihan jasmani atau olahraga sangat penting dalam penatalaksanaan diabetes karena efeknya dapat menurunkan kadar glukosa darah dengan meningkatkan pengambilan glukosa oleh otot dan memperbaiki pemakaian insulin (Zaenurokhim dan Andi, 2012).

Masalah DM ini harus mendapat perhatian yang serius karena dapat menyebabkan komplikasi. Menurut Robbins dan Cotran (2010) menyebutkan salah satu komplikasi penyakit DM adalah ulkus diabetikum. Ulkus diabetikum adalah kerusakan sebagian (partial thickness) atau keseluruh (full thickness) pada kulit, tendon, otot, tulang atau persendian yang terjadi pada seseorang yang menderita penyakit diabetes melitus (DM), kondisi ini timbul sebagai akibat terjadinya peningkatan kadar gula darah yang tinggi. Jika ulkus kaki berlangsung lama, tidak dilakukan penatalaksanaan dan tidak sembuh, luka akan menjadi infeksi. Ulkus kaki, infeksi, neuropati dan penyakit arteri perifer seringmengakibatkan gangren dan amputasi ekstremitas bagian bawah (Karminah, 2019).

Seiring dengan peningkatan jumlah penderita DM, maka komplikasi yang terjadi juga semakin meningkat, satu diantaranya adalah ulserasi yang mengenai tungkai bawah, dengan atau tanpa infeksi dan menyebabkan kerusakan jaringan di bawahnya yang selanjutnya disebut dengan kaki diabetes (KD). Manifestasi KD dapat berupa dermopati, selulitis, ulkus, gangrene, dan osteomyelitis. Dermopati akan menyebabkan kuku rentan akan infeksi, folikulitis dan sties, Selulitis akan menyebabkan kulit kemerahan, bengkak, terasa lembek dan sakit saat ditekan, ulkus menyebabkan penyempitan pembuluh darah, kerusakan struktur tulang kaki. Kesemuanya akan menyebabkan luka, apabila luka terjadi pada kaki diabetik akan beresiko menyebabkan terjadinya ulkus diabetikum (Sunaryo dan Sudiro, 2014).

Prevalensi DM Tipe 2 dengan ulkus diabetikum dari tahun ke tahun semakin meningkat, di dunia berkisar 4-10\%, yang menyebabkan 40-7-\% kasus DM Tipe 2 dengan ulkus diabetik mengalami amputasi dengan non trauma. Penyebab terjadinya amputasi yaitu diakibatkan oleh faktor iskemik 50-7-\%, dan komplikasi dengan infeksi 30-50\% (Karminah, 2019). Prevalensi ulkus diabetikum di Indonesia sebesar 15\%dengan presentasi kematian 32,5\% dan presentasi dengan amputasi sebesar 23,5\%, dan presentasi jumlah perawatan penderita DM di rumah sakit sebesar 80\% (Wagiu, 2016).

Latihan jasmani akan menyebabkan terjadinya peningkatan aliran darah, maka akan lebih banyak jala-jala kapiler terbuka sehingga lebih banyak tersedia reseptor insulin dan reseptor menjadi lebih aktif yang akan berpengaruh terhadap penurunan glukosa darah pada pasien diabetes (Sunaryo dan Sudiro (2014). Contoh latihan jasmani atau olahraga yang dianjurkan salah satunya adalah senamkaki diabetes. Senam direkomendasikan dilakukan dengan intensitas moderat (60-70 maksimum heart rate), durasi 30-60 menit, dengan frekuensi 3-5 kali per minggu dan tidak lebih dari 2 hari berturut-turut tidak melakukan senam (Ruben, dkk, 2016)

Berdasarkan penelitian yang dilakukan oleh Hondro (2011) dengan Judul "Pengaruh Senam Diabetes Melitus Terhadap Kadar Glukosa Darah Pada Penderita Diabetes Melitus Tipe 2 di Desa Darusalam Medan 2011" menunjukan adanya efektivitas senam diabetes melitus dapat menurunkan kadar gula darah pada penderita diabetes melitus tipe 2. Hal ini didukung oleh penelitian Karinda (2013) yang berjudul "Pengaruh Senam Sehat Diabetes Melitus Terhadap Profil Lipid Pasien Diabetes Melitus Tipe 2 di Desa Patrang Kabupaten Jember" diketahui bahwa terdapat pengaruh senam diabetes melitus terhadap profil lipid pasien diabetes melitus tipe 2. Menurut Karinda (2013) senam tersebut dilakukan dengan gerakan ritmis yang dilakukan 3 kali dalam seminggu selama 1 bulan dengan durasi latihan 30-60 menit.

Berdasarkan hasil survey awal yang dilakukan di Puskesmas Taupah Barat penyakit Diabetes Mellitus Tipe 2 menempati urutan ke 3 dari banyaknya kunjungan di tahun 2018 setelah penyakit Ispa dan Gastritis dimana kunjungan rata- rata usia 40 tahun keatas (data kunjungan puskesmas) dengan prevalensi jumlahnya sebanyak 65 orang. Kemudian terjadi peningkatan dari Januari sampai dengan November 2019 jumlah kunjungan penderita Diabetes Mellitus di Puskesmas Taupah Barat sebanyak 72 orang.

Berdasarkan hasil wawancara yang peneliti lakukan kepada 10 orang penderita diabetes 6 orang diantaranya menyebutkan belum pernah dan tidak mengetahui tentang senam kaki diabetik sedangkan 4 orang diantaranya menyatakan pernah mendengar mengenai senam kaki diabetik namun tidak pernah melaksanakannya. Berdasarkan uraian latar belakang diatas peneliti merasa tertarik melakukan penelitian dengan judul: "Pengaruh Senam Kaki Diabetik Terhadap Penurunan Risiko Ulkus Diabetikum pada Pasien Diabetes Mellitus Tipe 2 di Puskesmas Taupah Barat Kecamatan Taupah Barat Kabupaten Simeule Tahun 2020.

\section{RESEARCH METHOD}

Penelitian ini menggunakan analisis statistik parametrik dengan desain Pre-Experimental Design dengan pendekatan one-group pretest-posttes design yaitu untuk mengetahui Pengaruh Senam Kaki Diabetik 
Terhadap Penurunan Risiko Ulkus Diabetikum pada Pasien Diabetes Mellitus Tipe 2 di Puskesmas Taupah Barat Kecamatan Taupah Barat Kabupaten Simeule Tahun 2020. Populasi dalam penelitian ini adalah seluruh penderita diabetes mellitus yangberkunjung di Puskesmas Taupah Barat Kecamatan Taupah Barat Kabupaten Simeule sebanyak 32 orang. Teknik pengambilan sampel menggunakan teknik purposive sampling sebanyak 20 orang yang ditentukan berdasarkan pasien telah memenuhi kriteria inklusi dan ekslusi dalam penelitian ini. Analisis statistik data yang digunakan pada penelitian ini berupa univariant dan bivarian yaitu mengunakan paired-sample t test.

\section{RESULTS AND ANALYSIS}

\subsection{Hasil}

1. Karakteristik Responden

Karakteristik responden yang diteliti dalam penelitian ini meliputi: Umur, jenis kelamin dan pekerjaan responden diabetes mellitus tipe 2 dapat dilihat pada tabel:

Tabel 1. Karakteristik Responden di Puskesmas Taupah Barat Kecamatan Taupah Barat Kabupaten Simeule Tahun 2020

\begin{tabular}{clcc}
\hline No & Karakteristik & Frekuensi (f) & Persentase (\%) \\
\hline 1 & Umur & & \\
\hline & 40-50 Tahun & 9 & 45,0 \\
\hline & 51-60 Tahun & 7 & 35,0 \\
\hline & 61-70 Tahun & 2 & 10,0 \\
\hline >70 Tahun & 2 & 10,0 \\
\hline Jumlah & $\mathbf{2 0}$ & $\mathbf{1 0 0 , 0}$ \\
\hline J Jenis Kelamin & & 65,0 \\
\hline \multicolumn{2}{l}{ Laki-laki } & 13 & 35,0 \\
\hline Perempuan & 7 & $\mathbf{1 0 0 , 0}$ \\
\hline Jumlah & Pekerjaan & $\mathbf{2 0}$ & \\
\hline & Petani & & 45,0 \\
\hline & Nelayan & 9 & 45,0 \\
\hline & Pensiunan & 9 & 10,0 \\
\hline Jumlah & 2 & $\mathbf{1 0 0 , 0}$ \\
\hline
\end{tabular}

Berdasarkan tabel 1 dapat dilihat dari 20 orang pasien diabetes mellitus di Puskesmas Taupah Barat Kecamatan Taupah Barat dapat dilihat bahwa umur responden sebagian besar pada umur 40-50 tahun sebanyak 9 orang (45\%), jenis kelamin responden sebagian besar adalah laki-laki sebanyak 13 orang (65\%) dan pekerjaan responden sebagian besar adalah petani dan nelayan yakni masing-masing sebanyak 9 orang $(45 \%)$.

\section{Risiko Ulkus Diabetikum sebelum Pelaksanaan Senam Kaki Diabetik di Puskesmas Taupah Barat}

Untuk melihat hasil distribusi frekuensi risiko ulkus diabetikum sebelum pelaksanaan senam kaki diabetik di puskesmas taupah barat Kabupaten Simeule dapat dijabarkan pada Tabel 2:

Tabel 2. Gambaran Resiko Ulkus Diabetikum Responden Sebelum Dilakukan Senam Kaki Diabetik

\begin{tabular}{clcccccc}
\hline \multirow{2}{*}{ No } & \multirow{2}{*}{ Faktor Risiko } & \multicolumn{4}{c}{ Jawaban } & \multicolumn{2}{c}{ Total } \\
\cline { 3 - 7 } & & \multicolumn{2}{c}{ Ya } & \multicolumn{2}{c}{ Tidak } & \multicolumn{2}{c}{ N } \\
\cline { 3 - 7 } & Neuropati Perifer & 20 & 100,0 & 0 & 0 & 20 & 100,0 \\
\hline 1 & Gangguan vaskular perifer & 19 & 95,0 & 1 & 5,0 & 20 & 100,0 \\
\hline 2 & 1 & 5,0 & 19 & 95,0 & 20 & 100,0 \\
\hline 3 & Riwayat ulkus kaki & 0 & 0 & 20 & 100,0 & 20 & 100,0 \\
\hline 4 & Riwayat amputasi & 9 & 45,0 & 11 & 55,0 & 20 & 100,0 \\
\hline 5 & Deformitas & 0 & 0 & 20 & 100,0 & 20 & 100,0 \\
\hline 6 & Gangguan mobilisasi & 11 & 55,0 & 9 & 45,0 & 20 & 100,0 \\
\hline 7 & Kondisi kuku patologik & &
\end{tabular}

Berdasarkan tabel 2 dapat dilihat bahwa sebagian besar pasien diabetes mellitus mengalami neurofati perifer yaitu sebanyak 20 orang (100\%), gangguan vaskkuler sebanyak 19 orang (95\%), riwayat ulkus kaki sebanyak 1 orang (5\%), deformitas sebanyak 9 orang (45\%), kondisi kuku patologik sebanyak 11 orang $(55 \%)$ dan tidak ada pasien dengan kategori riwayat amputasi dan gangguan mobilisasi. 
Tabel 3. Distribusi Frekuensi Risiko Ulkus Diabetikum sebelum Pelaksanaan Senam Kaki Diabetik di Puskesmas Taupah Barat Kecamatan Taupah Barat Kabupaten Simeule Tahun 2020

\begin{tabular}{clcc}
\hline No & $\begin{array}{l}\text { Risiko Ulkus Diabetikum Sebelum } \\
\text { Senam Kaki Diabetikum }\end{array}$ & $\begin{array}{c}\text { Frekuensi } \\
\text { (f) }\end{array}$ & \% \\
\hline 1 & Risiko rendah & 8 & 40,0 \\
\hline 2 & Risiko Tinggi & 12 & 60,0 \\
\hline & Jumlah & $\mathbf{2 0}$ & $\mathbf{1 0 0}$ \\
\hline
\end{tabular}

Dari tabel 2 dapat dilihat bahwa frekuensi risiko ulkus diabetikum sebelum pelaksanaan senam kaki diabetes di puskesmas taupah barat kecamatan taupah barat adalah sebagian besar risiko tinggi sebanyak 12 orang $(60 \%)$, dan minoritas risiko rendah sebanyak 8 orang $(40 \%)$.

3. Risiko Ulkus Diabetikum Sesudah Pelaksanaan Senam Kaki Diabetik di Puskesmas Taupah Barat

Untuk melihat hasil distribusi frekuensi risiko ulkus diabetikum setelah pelaksanaan senam kaki diabetik di Puskesmas Taupah Barat Kabupaten Simeule dapat dijabarkan pada Tabel 4:

Tabel 4. Gambaran Resiko Ulkus Diabetikum Responden Setelah Dilakukan Senam Kaki Diabetik

\begin{tabular}{|c|c|c|c|c|c|c|c|}
\hline \multirow{3}{*}{ No } & \multirow{3}{*}{ Faktor Risiko } & \multicolumn{4}{|c|}{ Jawaban } & \multirow{2}{*}{\multicolumn{2}{|c|}{ Total }} \\
\hline & & \multicolumn{2}{|c|}{ Ya } & \multicolumn{2}{|c|}{ Tidak } & & \\
\hline & & $\mathbf{F}$ & $\%$ & $\mathbf{F}$ & $\%$ & $\mathbf{N}$ & $\%$ \\
\hline 1 & Neuropati Perifer & 20 & 100,0 & 0 & 0 & 20 & 100,0 \\
\hline 2 & Gangguan vaskular perifer & 15 & 75,0 & 5 & 25,0 & 20 & 100,0 \\
\hline 3 & Riwayat ulkus kaki & 0 & 0 & 20 & 100,0 & 20 & 100,0 \\
\hline 4 & Riwayat amputasi & 0 & 0 & 20 & 100,0 & 20 & 100,0 \\
\hline 5 & Deformitas & 1 & 5,0 & 19 & 95,0 & 20 & 100,0 \\
\hline 6 & Gangguan mobilisasi & 0 & 0 & 20 & 100,0 & 20 & 100,0 \\
\hline 7 & Kondisi kuku patologik & 3 & 15,0 & 17 & 85,0 & 20 & 100,0 \\
\hline
\end{tabular}

Berdasarkan tabel 4 dapat dilihat bahwa sebagian besar pasien diabetes mellitus mengalami neurofati perifer yaitu sebanyak 20 orang (100\%), gangguan vaskuler sebanyak 15 orang (75\%), deformitas sebanyak 1 orang (5\%), kondisi kuku patologik sebanyak 3 orang (15\%) dan tidak ada pasien dengan kategori riwayat amputasi, gangguan mobilisasi dan riwayat ulkus kaki.

Tabel 5. Distribusi Frekuensi Risiko Ulkus Diabetikum sesudah Pelaksanaan Senam Kaki Diabetik di Puskesmas Taupah Barat Kecamatan Taupah Barat Kabupaten Simeule Tahun 2020

\begin{tabular}{clcc}
\hline No & $\begin{array}{l}\text { Risiko Ulkus Diabetikum Sesudah Senam } \\
\text { Kaki Diabetikum }\end{array}$ & $\begin{array}{c}\text { Frekuensi } \\
\text { (f) }\end{array}$ & \% \\
\hline 1 & Risiko rendah & 17 & 85,0 \\
\hline 2 & Risiko Tinggi & 3 & 15,0 \\
\hline & Jumlah & $\mathbf{2 0}$ & $\mathbf{1 0 0}$ \\
\hline
\end{tabular}

Dari tabel 5 dapat dilihat bahwa frekuensi risiko ulkus diabetikum sesudah pelaksanaan senam kaki diabetes di puskesmas taupah barat kecamatan taupah barat adalah sebagian besar risiko rendah sebanyak 17 orang $(85 \%)$, dan minoritas risiko tinggi sebanyak 3 orang $(15 \%)$.

4. Pengaruh sebelum dan sesudah pelaksanaan Senam Kaki Diabetik Terhadap Penurunan Risiko Ulkus Diabetikum pada Pasien Diabetes Mellitus Tipe 2 di Puskesmas Taupah Barat Kecamatan Taupah Barat Kabupaten Simeule Tahun 2020

Untuk melihat pengaruh sebelum dan sesudah pelaksanaan senam kaki diabetik terhadap penurunan risiko ulkus diabetikum pada pasien diabetes mellitustipe 2 di Puskesmas Taupah Barat Kabupaten Simeule tahun 2020 dapat dilihat pada Tabel 6:

Tabel 6. Pengaruh sebelum Dan Sesudah Pelaksanaan Senam Kaki Diabetik Terhadap Penurunan Risiko Ulkus Diabetikum pada Pasien Diabetes Mellitus Tipe 2 di Puskesmas Taupah Barat Kecamatan Taupah Barat Kabupaten Simeule Tahun 2020

\begin{tabular}{clcccc}
\hline \multirow{2}{*}{ No } & \multirow{2}{*}{ Senam Kaki Diabetik } & \multicolumn{4}{c}{ Risiko Ulkus Diabetikum } \\
\cline { 3 - 5 } & & Mean & Lower & Upper & Sig \\
\hline 1 & Sebelum Senam & 2,90 & \multirow{2}{*}{0,535} & 1,365 & 0,001 \\
2 & Sesudah Senam & 1,95 & & \\
\hline
\end{tabular}

Berdasarkan Tabel 6 dapat dilihat bahwa terdapat perbedaan nilai rata-rata sebelum dan sesudah dilakukan senam kaki diabetik dengan nilai 2,90 (sebelum senam kaki diabetik) dan menurun menjadi 1,95 
(sesudah dilakukan senam dkai diabetik). Kemudian dilihat dari nilai lower bound dan upper bound dapat diinterpretasikan bahwa pasien yang mengalami diabetes mellitus tipe 2 lebih beresiko sebesar 0,535 kali lipat dapat mengalami ulkus diabetikum dan paling besar lebih beresiko sebesar 1,365 kali lipat dapat menderita ulkus diabetikum apabila tidak dilakukan senam kaki diabetik.

Kemudian berdasarkan hasil uji Paired Sample -Test didapatnilai $p=0,0001<\alpha=0,05$ maka $\mathrm{H}_{0}$ ditolak artinya terdapat Pengaruh sebelum dan sesudah pelaksanaan Senam Kaki Diabetik Terhadap Penurunan Risiko Ulkus Diabetikum pada Pasien Diabetes Mellitus Tipe 2 di Puskesmas Taupah Barat Kecamatan Taupah Barat Kabupaten Simeule Tahun 2020.

\subsection{Pembahasan}

1. Distribusi Frekuensi Risiko Ulkus Diabetikum sebelumPelaksanaan Senam Kaki Diabetik di Puskesmas Taupah Barat Kecamatan Taupah Barat Kabupaten Simeule Tahun 2020

Berdasarkan hasil frekuensi risiko ulkus diabetikum sebelum pelaksanaan senam kaki diabetes di Puskesmas Taupah Barat Kecamatan Taupah Barat adalah sebagian besar risiko tinggi

Ulkus diabetikum dapat terjadi akibat kadar gula darah yang relatif tinggi. Menurut Ruben dkk (2016) menyebutkan bahwa kadar gula darah yang relatif tinggi ini dipengaruhi oleh beberapa faktor diantaranya pola diet dan aktivitas.

Faktor pencetus terjadinyapeningkatan kadar gula darah merupakanakibat dari gaya hidup yang salah dan kurangnya aktivitas fisik. Penggunaan aktivitas fisik disini yaitu energi untuk aktivitas fisik yang berisiko terhadap kejadian ulkus ditempat kerja seperti pekerjaan petani dan nelayan yang menggunakan aktifitas fisik moderat namun mempunyai risiko tinggi untuk luka pada saat bekerja yang dapat menyebabkan risiko tinggi ulkus pada pasien. Namun penggunaan aktifitas fisik ini lebih baik dibandingkan dengan aktifitas yang kurang baik seperti duduk-duduk bersila sambil nonton tv, bersantai dan lain-lain. Menurut Penelitian Mitasari dkk (2014) menyebutkan bahwa Orang yang banyak berdiam diri atau kurang gerak mempunyai resiko lebih besar menderita DM, dibandingkan seseorang yang banyak aktivitas fisik.

Ditinjau dari pekerjaan responden adalah petani dan nelayan yang tetap beresiko luka pada saat bekerja, hal ini sesuai dengan menurut hasil penelitian Ferawati (2014) dimana responden paling banyak yaitu bekerja sebagai petani. Diabetisi tidak boleh berjalan tanpa alas kaki karena tanpa menggunakan alas kaki yang tepat memudahkan terjadi trauma yang mengakibatkan ulkus diabetik, terutama apabila terjadi neuropati yang mengakibatkan sensasi rasa berkurang atau hilang. penderita ulkus diabetik yang tidak menggunakan alas kaki dengan benar dan tepat dikarenakan ketidaktahuan dan kurangnya pengetahuan mengenai kaki diabetes yang mereka peroleh. Diabetisi tidak boleh berjalan tanpa alas kaki karena tanpa menggunakan alas kaki yang tepat memudahkan terjadi trauma yang mengakibatkan ulkus diabetik, terutama apabila terjadi neuropati yang mengakibatkan sensasi rasa berkurang atau hilang (Lestari D.D et all, 2013).

\section{Distribusi Frekuensi Risiko Ulkus Diabetikum setelahPelaksanaan Senam Kaki Diabetik di Puskesmas Taupah Barat Kecamatan Taupah Barat Kabupaten Simeule Tahun 2020}

Hasil frekuensi risiko ulkus diabetikum sesudah pelaksanaan senam kaki diabetes di Puskesmas Taupah Barat Kecamatan Taupah Barat adalah sebagian besar risiko rendah. Hal ini menggambarkan terjadinya perbaikan risiko terjadinya ulkus setelah dilakukan senam kaki diabetik.

Setelah peneliti menjelaskan maksud dan tujuan dilakukan senam kaki diabetik menyebabkan responden aktif melakukan senam diabetik untuk menurunkan risiko tinggi ulkus diabetikum. Hal ini sesuai dengan pendapat yang dikemukakan oleh Yudono (2012) bahwa pada saat latihan (senam) kebutuhan energi meningkat sehingga otot menjadi lebih aktif dan terjadi peningkatan pemakaian glukosa sehingga terjadi penurunan kadar gula darah dan akan menyebabkan penurunan risiko ulkus diabetikum, hal ini juga dilatarbelakangi oleh faktor kontinuitas atau keteraturan pasien dalam mengikuti senam sehingga terjadi penurunan kadar gula darah.

Olahraga atau latihan fisik merupakan bagian yang tidak dapat dipisahkan dari perawatan penderita diabetes melitus disamping mentaati diet (terapi nutrisi medik), dan pemakaian obat-obatan baik penderita diabetes tipe 1 , maupun tipe 2 .

\section{Pengaruh sebelum dan sesudah pelaksanaan Senam Kaki Diabetik Terhadap Penurunan Risiko Ulkus Diabetikum pada Pasien Diabetes Mellitus Tipe 2 di Puskesmas Taupah Barat Kecamatan Taupah Barat Kabupaten Simeule Tahun 2020}

Senam adalah latihan fisik yang dipilih dan diciptakan dengan terencana, disusun secara sistematik dengan tujuan membentuk dan mengembangkan pribadi secara harmonis (Nasution, 2010). Senam kaki adalah kegiatan atau latihan yang dilakukan penderita diabetes untuk mencegah terjadinya luka dan membantu melancarkan peredaran darah pada kaki (Nasution, 2012). 
Senam kaki diabetik sangat penting dilakukan untuk mengurangi risiko ulkus diabetikum. Ulkus diabetikum merupakan luka terbuka pada permukaan kulit karena adanyakomplikasi makroangiopati sehingga terjadi vaskuler insusifiensi dan neuropati, keadaan lebih lanjut terdapat luka pada penderita yang sering tidak dirasakan, dan dapat berkembang menjadi infeksi disebabkan oleh bakteri aerob maupun anaerob (Prasetyorini, 2015).

Pasien dengan risiko ulkus diabetikum dalam penelitian ini beresiko pada umur responden sebagian besar pada umur 40-50 tahun sebanyak 9 orang (45\%), jenis kelamin responden sebagian besar adalah lakilaki sebanyak 13 orang $(65 \%)$ dan pekerjaan responden sebagian besar adalah petani dan nelayan yakni masing-masing sebanyak 9 orang $(45 \%)$.

Berdasarkan Tabel diatas dapat dillihat bahwa terdapat perbedaan nilai rata-rata sebelum dan sesudah dilakukan senam kaki diabetikdengan nilai 2,90 (sebelum senam kaki diabetik) dan menurun menjadi 1,95 (sesudah dilakukan senam kaki diabetik). Kemudian dilihat dari nilai lower bound dan upper bound dapat diinterpretasikan bahwa pasien yang mengalami diabetes mellitus tipe 2 lebih beresiko sebesar 0,535 kali lipat dapat mengalami ulkus diabetikum dan paling besar lebih beresiko sebesar 1,365 kali lipat dapat menderita ulkus diabetikum apabila tidak dilakukan senam kaki diabetik.

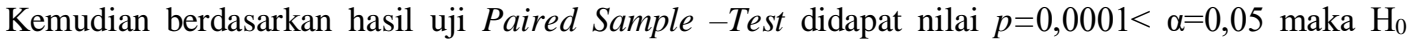
ditolak artinya terdapat Pengaruh sebelum dan sesudah pelaksanaan Senam Kaki Diabetik Terhadap Penurunan Risiko Ulkus Diabetikum pada Pasien Diabetes Mellitus Tipe 2 di Puskesmas Taupah Barat Kecamatan Taupah Barat Kabupaten Simeule Tahun 2020.

Menurut penelitian Sunaryo dan Sudiro (2014) menyebutkan bahwa terdapat pengaruh senam diabetik terhadap penurunan resiko ulkus kaki diabetik. Selanjutnya dari hasil uji regresi logistik sederhana diperoleh nilai OR (Odds Rasio) 1,238 artinya pasien yang yang mengikuti senam diabetik memiliki peluang menurunkan resiko ulkus diabetik sebanyak 1 kali dibandingkan penderita DM yang tidak mengikuti senam.

Hal ini didukung oleh penelitian Suryanto (2010) yang menyebutkan bahwa terdapat pengaruh senam diabetik terhadap penurunan resiko ulkus kaki diabetik dengan nilai OR (Odds Rasio) 1,238 artinya pasien yang yang mengikuti senam diabetik memiliki peluang menurunkan resiko ulkus diabetik sebanyak 1 kali dibandingkan penderita DM yang tidak mengikuti senam.

Senam diabetik secara rutin secara significan mempengaruhi vaskulerisasi ekstremitas bawah dan mencegah Peripheral Arterial Disease serta mempertahankan nilai normal Ankle Brachial Index (Mohler ER, et.al, 2013). Menurut asumsi peneliti senam diabetik secara simultan berpengaruh pada penurunan risiko ulkus diabetikum. Artinya, semakin teratur dilakukan senam kaki diabetik maka akan semakin efektif terhadap penurunan risiko ulkus diabetikum.

\section{CONCLUSION}

Berdasarkan penelitian yang dilakukan di Puskesmas Taupah Barat Kecamatan Taupah Barat Kabupaten Simeule didapatkan kesimpulan:

1. Risiko ulkus diabetikum sebelum pelaksanaan senam kaki diabetes di Puskesmas Taupah Barat Kecamatan Taupah Barat adalah sebagian besar risiko tinggi.

2. Risiko ulkus diabetikum sesudah pelaksanaan senam kaki diabetes di puskesmas taupah barat kecamatan taupah barat adalah sebagian besar risiko rendah.

3. Terdapat Pengaruh sebelum dan sesudah pelaksanaan Senam Kaki Diabetik Terhadap Penurunan Risiko Ulkus Diabetikum pada Pasien Diabetes Mellitus Tipe 2 di Puskesmas Taupah Barat Kecamatan Taupah Barat Kabupaten Simeule Tahun 2020 dengan nilai $p=0,0001<\alpha=0,05$.

\section{REFERENCES}

American Diabetes Association (ADA). 2012. Medical advice for people with diabetes in emergency situations. American Diabetes Association Journal

American Diabetes Association. 2013. Position statement: Standards of Medical Care in Diabetes. [serial online] http://care.diabetesjournals.org/ content/33/Supplement_1/S11.full.pdf+html.

Ferawati. I . 2014. Faktor-faktor yang mempengaruhi terjadinya ulkus diabetikum pada pasien DM Tipe 2 di RSUD Prof. Dr. Margono Soekarjo Purwokerto: Universitas Jendral Sudirman. Diperoleh dari http://keperawatan.unsoed.ac.id pada tanggal 10 Desember 2019

Hondro, E., \& Sinaga, J. 2011. Pengaruh Senam Diabetes Melitus Terhadap Kadar Glukosa Darah Pada Penderita Diabetes Melitus Tipe 2 Di Wilayah Kerja Puskesmas Darusalam Medan 2011.

Karinda, R. A. 2013. Pengaruh Senam Sehat Diabetes Mellitus Terhadap Profil Lipid Klien Diabetes Mellitus Tipe 2 Di Wilayah Kerja Puskesmas Patrang Kabupaten Jember [skripsi] Jember: Program Studi Ilmu Keperawatan Universitas Jember.

Karminah, 2019. Asuhan Keperawatan pada Pasien yang Mengalami Ulkus Diabetikum dengan Masalah Keperawatan Kerusakan integritas Jaringan di Ruang Kenanga RSUD Dr. H. Abdul Moeloek Provinsi Lampung Tahun 2019. KTI. STIKes Muhammadiyah Pringsewu Lampung. 
Lestari DD, et all .2013. Gambaran Kadar Glukosa Puasa Pada Mahasiswa Angkatan 2011 Fakultas Kedokteran Sam Ratulangi Dengan IMB 18,5 - 22,9 kg/m . Jurnal e-Biomedik (eBM) Vo; 1 No. 2 Hal.991-996

PERKENI.2015. Konsensus Pengelolaan dan Pencegahan Diabetes Militus Tipe 2 di Indonesia.

PERKENI.2015. Konsensus Pengelolaan dan Pencegahan Diabetes Militus Tipe 2 di Indonesia.

Prasetyorini, D.A, 2015. Pengaruh Latihan Senam Diabetes Mellitus Terhadap Risiko Terjadinya Ulkus Diabetik pada Pasien Diabetes Mellitus Tipe 2 Di Desa Rambipuji Kecamatan Rambipuji Kabupaten Jember. Skripsi. Universitas Jember.

Ruben, dkk, 2016. Pengaruh Senam Kaki Diabetes terhadap Perubahan Kadar Gula Darah pada Pasien Diabetes Mellitus Tipe 2 di Wilayah Kerja Puskesmas Enemawira. Ejournal Keperawatan (eKp) Vol. 4 Nomor 1

Ruben, G, dkk, 2016. Pengaruh Senam Diabetes Terhadap Perubahan Kadar Gula Darah Pada Pasien Diabetes Mellitus Tipe 2 di Wilayah Kerja Puskesmas Enemawira. Jurnal Keperawatan Vol. 4 Nomor 1.

Robbins, \& Cotran. (2010). Dasar Patologis Penyakit (7 ed.). (V. Kumar, A. K. Abbas, N. Fausto, Eds., L. Y. Rachman, F. Dany, \& L. Rendy, Trans.) Jakarta: EGC.

Sunaryo T, Sudiro, 2014. Pengaruh Senam Diabetik Terhadap Penurunan Resiko Ulkus Kaki Diabetik Pada Pasien DM Tipe 2 Di Perkumpulan Diabetik. Jurnal Terpadu Ilmu Kesehatan Vol. 3 No. 1

Sunaryo, T dan Sudiro, 2014. Pengaruh Senam Diabetik Terhadap Penurunan Resiko Ulkus Kaki Diabetik pada Pasien DM Tipe 2 di Perkumpulan Diabetik. Jurnal Terpadu Ilmu Kesehatan. Vol. 3. Nomor 1. Lm 99-105.

Sutedjo, A. Y. 2010. 5 Strategi Penderita Diabetes Mellitus Berusia Panjang. Jogjakarta : Kanisius.

World Health Organization. (2012, November 14). WHO. Retrieved 5 3, 2013, from WHO web site: ttp://www.who.int/topics/diabetes_mellitus/en/

Yudhono, P.T, 2012. Pengaruh terapi senam kaki terhadap penurunan glukosa darah pada Lansia dengan diabetes mellitus di posyandu lansia desa ledug kecamatan kembaran bayumas.

Zaenurokhim K A dan Andi,M. (2012). Pengaruh Senam Kaki Diabetes Terhadap Perubahan Tekanan Darah Pada Klien DM Tipe 2. 